\title{
A CROSS SECTIONAL STUDY OF CORONARY HEART DISEASE IN URBAN SLUM POPULATION OF MUMBAI
}

\author{
WAINGANKAR P.J. ${ }^{*}$ AND PANDIT D.D. ${ }^{2}$ \\ 'Department of Community Medicine, M.G.M. Medical College, Navi Mumbai, MS, India. \\ 2Department of Community Medicine, Terna Medical college, Navi Mumbai, MS, India. \\ ${ }^{*}$ Corresponding Author: Email- wprasad67@gmail.com
}

Received: June 08, 2012; Accepted: June 28, 2012

\begin{abstract}
Apart from widespread clinical impression of a rapid spurt in the proportion of cases with Coronary heart Disease (CHD) being evaluated by various levels of medical practice there are demographic and social reasons to apprehend a major epidemic of CHD in India and other developing countries. A major chunk of Indian population stays in urban slums and Mumbai has a large share in it. Such large population always go ignored when people assume that coronary heart disease is a disease of affluence, while poverty is no bar for coronary heart disease. The objectives of present study are to find out prevalence of Coronary Heart Disease (CHD) in the age group of 25 to 64 years in urban slum community in Mumbai and to study various factor associated with it, also to study the level of knowledge about CHD and its risk factors among the subjects. The present study was designed to be a cross-sectional study conducted in an urban slum, community with a population of 35,967, served by Urban Health Centre, attached to the department of Preventive and Social Medicine of teaching institute. CHD was diagnosed using Rose Questionnaire and/or documentary evidence of Ml. Total 186 cases (126 males and 60 females) of $\mathrm{CHD}$ were found in the community and prevalence of $\mathrm{CHD}$ was 15.80 per thousand. It was maximum (99.11 per thousand) in the age group of 55-64 years. Majority of cases were Muslims as the community was predominantly having Muslim population. The rate of detection of new cases increases with increasing age in both sexes, especially, more among females. Proportion of newly detected cases in males is $45.2 \%$ and in females $61.7 \%$. In the age group of 55 to 64 years 81 males $(75.7 \%)$ and 31 females $(81.6 \%)$ were suffering from hypertension. The mean systolic blood pressure of all 186 subjects was 161.8 (SD-18.4 \& SE-1.35) while mean diastolic blood pressure was 97.6 (SD-10.3 \& SE-0.76). The 6 males (4.8\%) and 11 females (18.3\%) were suffering from Diabetes among the study group. The mean total cholesterol was 255.30 (SD-41.1 SE-3.0). Only 13 cases (7\%) had total cholesterol levels were below $200 \mathrm{mg} / \mathrm{dl}$ while $73 \%$ had levels above $240 \mathrm{mg} / \mathrm{dl}$. The 51 cases (27.4\%) were receiving 2800 or more calories through daily diet. But only $3.8 \%$ cases were eating fats amounting $30 \%$ or more of total calories. Among cases $66.7 \%$ were smokers while $39.8 \%$ had given history of passive smoking. The study findings show that knowledge about CHD and its risk factor is very poor in general. To obtain a composite picture for the whole country, large community based epidemiological studies will have to be conducted in different parts of the country. It will help the policy makers to chalk out programmes to minimize the extent of the problem of $\mathrm{CHD}$.
\end{abstract}

Key words- CHD, Epidemiology, Urban, NCD

Citation: Waingankar P.J. and Pandit D.D. (2012) A Cross sectional study of Coronary Heart Disease in Urban Slum Population of Mumbai. International Journal of Medical and Clinical Research, ISSN:0976-5530 \& E-ISSN:0976-5549, Volume 3, Issue 5, pp.-180-189.

Copyright: Copyright@2012 Waingankar P.J. and Pandit D.D. This is an open-access article distributed under the terms of the Creative Commons Attribution License, which permits unrestricted use, distribution and reproduction in any medium, provided the original author and source are credited.

\section{Background}

Chronic Non-communicable diseases are assuming increasing importance among adult population in both developed and developing countries. Cardiovascular diseases (CVD), a leading cause of death among these, are a public health problem affecting both sexes despite significant medical advances globally.
The 29th World Health Assembly held in 1976 and 36th World Health Assembly held in 1983, both have passed the resolutions (WHA 29.49 \& WHA 36.23 respectively) which identified cardiovascular diseases as:

i. Main cause of morbidity and mortality in all developed countries. 
ii. Of increasing significance as a cause of ill health and death in many developing country [1].

In developing countries CVD account for smaller proportion of all deaths than in the developed ones. But the greater contribution of CVD deaths in developing countries to mortality worldwide means that the total number of deaths from these diseases is even greater there than in developed countries [2].

Cardiovascular Diseases (CVD) are already a major cause of morbidity and mortality in India. The threat of CVD is growing and the health services will face formidable challenge of a major epidemic of CVD in this century itself, if adequate preventive measures to pre-empt it are not urgently initiated and vigorously pursued. Apart from widespread clinical impression of a rapid spurt in the proportion of cases with Coronary heart Disease (CHD) being evaluated by various levels of medical practice there are demographic and social reasons to apprehend a major epidemic of CHD in India and other developing countries. The increasing prevalence of $\mathrm{CHD}$ in the young and the impact on longevity from control of communicable diseases necessitates concerned effort by scientists, policy makers and planners towards controlling cardiovascular and related health problems in our country today.

In Coronary Heart Disease the underlying morbid process develops insidiously and only late in its natural history doses clinical illness supervenes. Sometimes the sufferer has no warning of his condition and dies suddenly, of all events. Only rarely does the clinician have the opportunity to examine a patient before there has been major damage within cardio-vascular system. In the history of medicine no disease has ever been conquered by an attempt to treat every affected individual. It is only by studying the aetiology through the epidemiologic approach that man has been able to stamp out mass disease.

There is a growing interest in aetiology, in the identification of susceptible individuals and in the development of preventive measures. All of these involve and epidemiological approach. The use of mortality and morbidity statistics has played an important role in this approach by indicating where the main problems of chronic disease lie and by suggesting the hypotheses for further investigation. Such inquiries will continue to be useful, but their conclusions at best be tentative; there is a great need to test and extend their findings and to collect more direct evidence on causation by personal examination and following of suitable population groups. This need is widely recognized and clinicians in many parts of the world have extended their studies from hospitals to the general population.

Clinical research and epidemiology differ from one another both in their strengths and limitations. It is possible to study the characteristics of patients in hospital with a thoroughness that can seldom be matched in a population study; and most aetiological hypotheses have originated from clinical and laboratory observations. At the same time the inferences that can be drawn from clinical observations are limited in number of respects.

A major chunk of Indian population stays in urban slums and Mumbai has a large share in it. Such large population always go ignored when people assume that coronary heart disease is a disease of affluence, while poverty is no bar for coronary heart disease.
In the light of such considerations an attempt has been made to assess the prevalence of Coronary heart Disease and role of various factors influencing it in an urban slum population.

\section{Aim and Objectives}

To study the epidemiology of Coronary Heart Disease in Urban Slum Population in Mumbai

Objectives

- To find out prevalence of Coronary Heart Disease (CHD) in the age group of 25 to 64 years.

- To study the various factors associated with Coronary Heart Disease.

- To study level of knowledge about Coronary heart Disease (CHD) and its risk factors in study group.

- To suggest recommendations on the basis of study findings.

\section{Methodology}

The present study was designed to be a cross-sectional study conducted in an urban slum community with a population of 35,967 , served by Urban Health Centre, attached to the department of Preventive and Social Medicine of teaching institute. The community was established in 1977 as a resettlement colony, in the south east part of Mumbai. It is bound by Thane creek on its eastern border. It consists of a total 11 sectors of varying sizes, starting from ' $A$ ' sector up to ' $K$ '. The ' $F$ ' sector is the largest in size and the ' $K$ ' sector is the smallest.

Each sector consists of a varying number of lines of kuchha or pucca houses, with houses in each row facing the opposite row of houses thus forming a pair. Most of the houses have maximum area of $10 \times 15$ square feet, comprising of a single room, with a 'mori' at one corner. Few houses have an additional floor. There are 20 common toilets for each sector and 2 common water taps for each line. The community has migration from Tamil Nadu, Kerala, Andhra Pradesh, Bihar, Uttar Pradesh and Maharashtra.

Since there are very few community based epidemiological studies of $\mathrm{CHD}$ in India, considering low prevalence rate of $\mathrm{CHD}$ and the need of large sample size [3], instead of taking the random sample, it was decided to cover the whole community by using door to door survey method. On the basis of evidence available in literature, study population was restricted to the age group of 25 64 years.

$\mathrm{CHD}$ was diagnosed if one or both of the following criteria were satisfied:

(a) History of chest pain as assessed by the official English version of Rose Questionnaire [4] to diagnose angina after excluding any obvious cause of pain due to local factors.

(b) Myocardial Infarction (MI) based on complaint of typical sever chest pain. Documentary evidence of $\mathrm{Ml}$ treated was insisted upon.

Effort was made to visit each and every authorised house, in serial order in each sector. A register was maintained in which number of persons in the age group of 25 to 64 years staying in the house was recorded age and sex wise. Those who had fulfilled the criteria for diagnosis of $\mathrm{CHD}$ were selected as cases. A pre-structured pre-tested questionnaire was used for data collection. The questionnaire was filled up only if the person was selected as a case. Details of some important variable are as follows: 
Age: Effort was made to find out the exact age in years using information available on Ration Card and asking relevant questions.

Socioeconomic Status: Being urban slum population per capita monthly income was used to determine socio-economic class as suggested by Gupta M.C., et al [5].

Family History: Family history of $\mathrm{CHD}$ or its risk factor was considered positive only if it was present in either of either parents or brothers or sisters.

Physical Activity: Physical activity was defined as light, moderate and heavy consistent with criteria recommended by expert Committee of WHO.

Dietary Habits: Twenty four hour recall method was used to assess the dietary habits of subjects. Special care was taken to estimate quantities of food consumed. Subjects were helped to estimate amounts by use of household measures and standard measures

Smoking: Those who had ever smoked cigarettes or bidis regularly for more than one year were labelled as smokers. Variation in number of cigarettes or bidis was taken in consideration by asking detail history and maximum number and period as well minimum number and period were recorded.

Alcohol Consumption: Those who have ever consumed alcohol regularly for more than one year were labelled as Alcohol consumers. Information about period and frequency of drinking alcohol was obtained.

Built: Ectomorph (linear, asthenic), Mesomorph (bony, muscular) and Endomorph (round, fat)

Hypertension: Blood pressure was recorded using stand guidelines [4]. Blood pressure recording in the sitting position was selected for analysis. Hypertension was defined as a systolic Blood Pressure of $160 \mathrm{~mm}$ of $\mathrm{Hg}$ or more and/or a diastolic blood pressure (Phase V) of more than $95 \mathrm{~mm}$ of $\mathrm{Hg}$ or history of hypertension with regular current consumption of antihypertensive drugs. Obesity: Obesity was estimated by using Body Mass Index (BMI) as suggested by WHO Expert committee [6].

ECG Findings: A 12 lead electrocardiogram at rest was obtained from all cases. Minnesota code [4] was used for diagnosis of ischemia as follows: (a) Pathological Q: code 1-1-1 through 1-1-7 or code 1-2-1 through 1-2-7 (b) Presence of major S. T. depression and/or a major T wave inversion in the absence of high voltage $R$ wave code 4-1-1 and 4-1-2 and 5-1 and 5-2

Lab investigations done included Urine Sugar, Albumin and Microscopic examination, Haemoglobin, Fasting and Post Lunch Blood Sugar and Serum Cholesterol. Though this is a non-interventional study all the newly detected Hypertensive, Diabetics and CHD Coronary Heart Disease patients were treated and referred to different institute as per the subject's need. Cases were given health education about coronary heart disease. This was done on ethical basis. Incidentally it helped in gaining $100 \%$ response for investigations.

The data was analysed on computer using SPSS package.

\section{Results and Discussion}

Total numbers of 11,772 individuals from Cheeta Camp Community were interviewed with Rose Questionnaire excluding $2.12 \%$ of non-respondents as shown in Table 1. Out of 35,967 of total popu-
Iation $33.43 \%$ were in the age group of 25 to 64 years. Total numbers of Coronary heart disease cases registered were 186.

It is difficult to compare the results of previous epidemiological studies with present one due to:

- Heterogeneity of population and different socio-cultural patterns existing in our country.

- Different criteria used in defining CHD

- Need of large sample size to study epidemiology of CHD

- The time difference between the various studies.

- Predominance of lower socio-economic status in urban slum population

Table 1- Area wise Population, Population covered and Proportion of Non-response

\begin{tabular}{|llllll|} 
Sector & $\begin{array}{l}\text { Total } \\
\text { Population }\end{array}$ & $\begin{array}{l}\text { Population } \\
\text { 25-64 Yrs. }\end{array}$ & $\begin{array}{l}\text { \%Population } \\
\text { 25-64 Yrs. }\end{array}$ & $\begin{array}{l}\text { Population } \\
\text { Interviewed }\end{array}$ & $\begin{array}{l}\text { Percentage of } \\
\text { Non-Response }\end{array}$ \\
\hline A & 2509 & 895 & 35.67 & 870 & 2.79 \\
B & 6195 & 2117 & 34.17 & 2027 & 4.25 \\
C & 2987 & 973 & 32.57 & 961 & 1.23 \\
D & 5654 & 1829 & 32.34 & 1808 & 1.15 \\
E & 3799 & 1134 & 29.84 & 1105 & 2.55 \\
F & 5003 & 1842 & 36.81 & 1828 & 0.76 \\
G & 4315 & 1497 & 34.69 & 1481 & 1.07 \\
H & 1498 & 518 & 34.57 & 507 & 2.12 \\
I & 596 & 221 & 37.08 & 216 & 2.26 \\
J & 1976 & 577 & 29.29 & 573 & 0.69 \\
K & 1453 & 424 & 29.54 & 396 & 6.60 \\
Total & 35,967 & 12,027 & 33.43 & 11,772 & 2.12 \\
\hline
\end{tabular}

\section{Prevalence of Coronary Heart Disease (CHD)}

As Table 2 shows, prevalence of CHD in Cheeta Camp was 15.80 per thousand in the age group of 25 to 64 years. In males it was 20.82 per thousand and in females it was 10.48 per thousand. It was highest (99.11 per thousand) in the age group of 55 to 64 years. In the age group of 45 to 54 years females had higher prevalence than males. There was marked and monotonic increase in prevalence with increase in age in both sexes.

Considering the total number of person in sample i.e. 12,027, minimum prevalence rate of $\mathrm{CHD}$ in Cheeta Camp was 15.46 per thousand in the age group of 25 to 64 years.

Table 2- Age \& Sex specific Prevalence of Coronary Heart Disease

\begin{tabular}{|c|c|c|c|c|c|c|c|c|c|}
\hline \multirow[b]{2}{*}{ Age } & \multicolumn{3}{|c|}{ Male } & \multicolumn{3}{|c|}{ Female } & \multicolumn{3}{|c|}{ Total } \\
\hline & $\begin{array}{l}\text { Pop. } \\
\text { Surveyed }\end{array}$ & Cases & $\begin{array}{l}\text { Prevalence } \\
\text { per } 1000\end{array}$ & $\begin{array}{l}\text { Pop. } \\
\text { Surveyed }\end{array}$ & Cases & $\begin{array}{l}\text { Prevalence } \\
\text { per } 1000\end{array}$ & $\begin{array}{l}\text { Pop. } \\
\text { Surveyed }\end{array}$ & Cases & $\begin{array}{l}\text { Prevalenc } \\
\text { per } 1000\end{array}$ \\
\hline $25-34$ & 2423 & - & - & 2224 & $1(1.7)$ & 0.45 & 4947 & $1(0.5)$ & 0.21 \\
\hline $35-44$ & 1676 & $4(3.2)$ & 2.38 & 1720 & $4(6.7)$ & 2.32 & 3396 & $8(4.3)$ & 2.35 \\
\hline $45-54$ & 1221 & $15(11.9)$ & 12.28 & 1045 & $17(28.3)$ & 16.26 & 2266 & $32(17.2)$ & 14.12 \\
\hline $55-64$ & 731 & $107(84.9)$ & 146.37 & 732 & $38(63.3)$ & 51.91 & 1463 & $145(78.0)$ & 99.11 \\
\hline Total & 6051 & $126(100)$ & 20.82 & 5721 & $60(100)$ & 10.48 & 11772 & $186(100)$ & 15.8 \\
\hline
\end{tabular}

Figures in parenthesis indicate column percentage

Age sex Distribution of Cases: Chi- Square $12.05 d f=3 P=$ 0.00719

The epidemiological survey carried out by Padmavati in adults over 20 years of age in general population of Delhi showed a prevalence of CHD of 55 per 1000 in high income group and 3.3 
per thousand in low income group [7]. The field survey by Mathur showed a prevalence of CHD 10.4 per thousand [8].

The study conducted by Gupta and Malhotra at Rohtak showed prevalence rates of $\mathrm{CHD}$ as 45.3 per thousand in men and 28.1 per thousand in women in the age group of 30 years and above [9]. But the criteria for diagnosis in this study were based on ECG findings. Sinha P.R., et al found prevalence of CHD $6.48 \%$ in the age group of 30 years and above in urban community of Varanasi [10].

Chadda S.L., et al found total prevalence of CHD 96.7 per thousand based on both clinical history and ECG criteria in the age group of 25 to 64 years, in the urban population of Delhi [11]. In this study Rose Questionnaire was used as one of the criteria to define $\mathrm{CHD}$ and limiting to this criteria prevalence rate of $\mathrm{CHD}$ was found 31.9 per thousand in the age group of 25-64 years. In males it was 39.5 per thousand, while in females 25.3 per thousand. In lower socio-economic status prevalence was 14.0 per thousand, 20 per thousand in males and 8.5 per thousand in females.

\section{Age and Sex}

Among 186 cases $126(67.7 \%)$ were males while $60(32.3 \%)$ were females as seen in Table 2. Out of total, $95.2 \%$ of cases belonged to age group of $45-64$ years and only $4.8 \%$ cases were in the age group of 25-44 years. The difference was found to be significant $(p<0.01)$. The male to female sex ratio was varying with age group. There was only one female $\mathrm{CHD}$ case in the age group of 25-34 years. In the age group of 35-44 the sex ratio was 1:1, in the age group of $45-54$ years it was 1:1.13 and in the age group of 55-64 years it was 1:0.35 while for the total range of 25 to 64 years it was 1:0.47. Mean age of cases was 57.14 years ranging from 33 to 64 years.

These results are consistent with the pattern reported in India [12]. The peak period is usually 51 to 60 years and males are found affected more than females. Chadda S.L. had found that out of 438 cases $252(57.38 \%)$ were males while $186(42.35 \%)$ were females [12]. The male to female ratio was 1: 0.74 in the age group of 25 to 64 years [11]. The $79 \%$ of cases were in the age group of 45 to 64 years while only $2.9 \%$ cases were in the age group of 25 to 34 years.

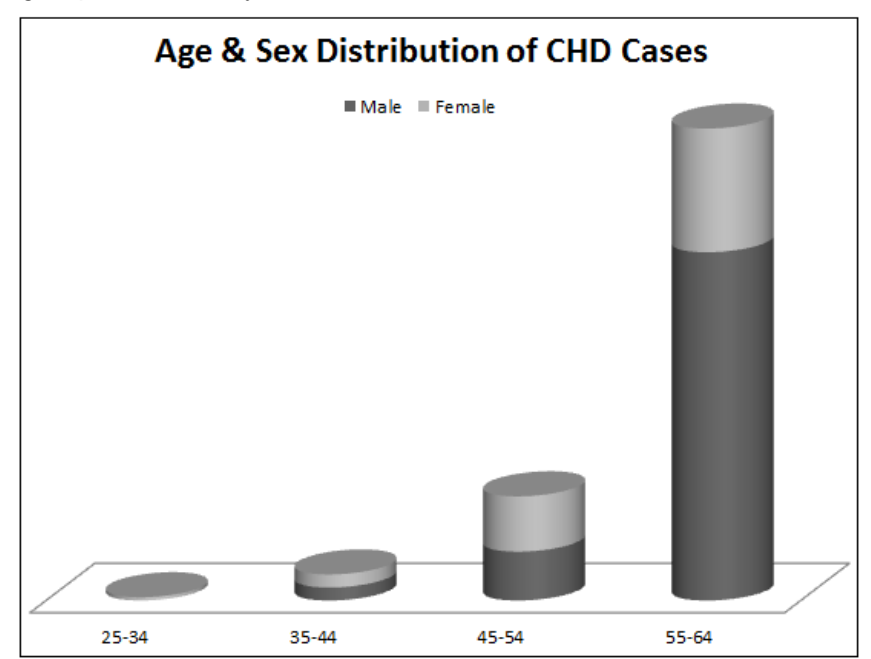

Fig. 1- Age and Sex Distribution of CHD Cases.

\section{Religion}

It was observed that majority of the cases (169/186: $90.9 \%)$ were Muslims and, the Hindu and the Christians were $14(7.5 \%)$ and 3 $(1.6 \%)$ respectively. This is consistent with predominance of Muslim population in community. Chadda S.L., et al had found that sex wise prevalence in Muslim population was 23.6 per 1000 in males and 16.9 per thousand in females [11]. While prevalence rates for non-Muslim population were 41.5 per 100 in males and 33.2 per 1000 in females. In present study the relevant data was not collected to calculate religion wise prevalence.

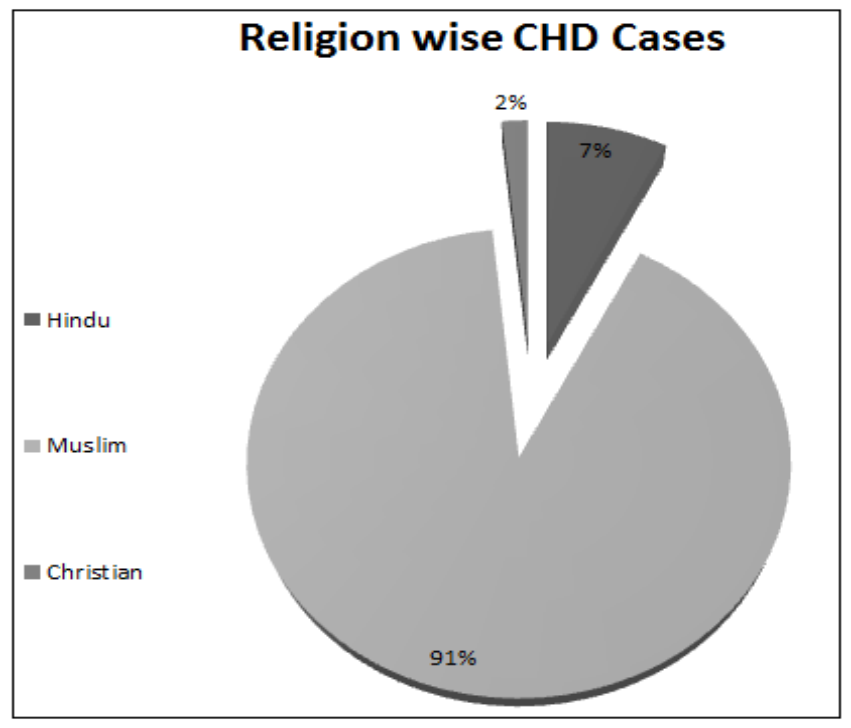

Fig. 2- Religion wise CHD Cases

\section{Family and Marital Status}

Mean duration of stay of the family in Cheeta camp was 14.6 years. The average family size was 5.95 . Out of 186 cases 103 (55.4\%) belonged to extended joint family while $54(29 \%)$ belonged to Joint family and $29(15.6 \%)$ were from unitary family. Maximum numbers of cases 104 (55.9\%) were having family size of 4 to 6 , while a significant number of cases $(69-37.1 \%)$ were having 7 to 9 family members in the family.

Out of 186 cases $165(88.7 \%)$ were married while $3(6 \%)$ were unmarried, $4(2.2 \%)$ were separated, $5(2.7 \%)$ were widowers and $9(4.8 \%)$ were widows. All the widowers were from the age group of $55-64$ years. Among widows $8(88.9 \%)$ were from the age group of 55 to 64 years while $1(11.1 \%)$ was from age group of 45 to 54 years. The single female case of $\mathrm{CHD}$ registered in the age group of 25 to 34 years was married.

Table 3 shows that observed difference in marital status of male and female cases was significant. $(p<0.01)$ In the older age group widow or widowers are more usually. Significance indicates only the presence of association and not the strength.

Table 3- Marital Status in Male and Female CHD Cases

\begin{tabular}{|llll|}
\hline Marital Status & Male & Female & Total \\
Married & $118(71.5)$ & $47(28.5)$ & $165(100)$ \\
Single & $8(38.1)$ & $13(61.9)$ & $21(100)$ \\
Total & $126(67.3)$ & $60(32.3)$ & $186(100)$ \\
\hline
\end{tabular}

Figures in parenthesis indicate row percentage Chi Square- $9.5208 d f=1 P<0.01$ 


\section{Education, Occupation and Income}

Total number of Illiterates were 120 (64.5\%), the $75(62.5 \%)$ of which were males and $45(37.5 \%)$ were females. The majority of illiterates i.e. 105 out of 120 were from age group of 55 to 64 years. Only $4(2.2 \%)$ were graduates. There was no significant difference $(P>0.05)$ in educational level of males and females among cases.

There were $9(4.8 \%)$ heavy workers among the subjects while 108 (58.1\%) were doing moderate type of work and $69(37.1 \%)$ were doing sedentary type of work. Out of $186,5(2.7 \%)$ were manual labourers. It was noted that $54.3 \%$ of cases worked less than 9 hours a day.

Out of 186 cases $135(72.6 \%)$ cases were having per capita monthly income of less than Rs. 500/-and belong to socioeconomic class IV or V. The 47 (25.3\%) subjects having per capita monthly income in the range of Rs. 500/- to Rs. 999/- belonged to Class III, while $2(1.1 \%)$ each belonged to Class I \& II. Among 125 cases there was only 1 earning member in the family, while in 53 cases 2 and in 8 cases 3 earning members were there in the family.

Padmavati, et al as well Chadda S.L., et al had found CHD more prevalent in higher socio-economic group $[7,11]$. In the present study the socio-economic status was determined only of the selected 186 subjects using Per Capita Income criteria. The high predominance of low socio-economic status in slum population is the limitation to draw a crystal clear conclusion.

\section{Physical Activity}

The 180 (96.8\%) subjects were not doing any kind of physical exercise, not even walking while among the remaining the cycling was most common type of exercise. The relationship between physical activity and the prevalence rate has been studied extensively by many workers and they reported that physical activity protects individual from the effect of CHD.

In epidemiological study of CHD in Gurgaon district sex wise prevalence in those who were doing heavy physical activity was found 8.0 in males and 5.5 in females [13]. Among those who were engaged in light physical activity the respective figures were 13.8 and 8.3 per thousand. Present study supports these findings.

\section{Family History}

The $21 \%$ of cases had given positive family history of CHD. Family history of smoking was present in $131(70.4 \%)$ cases. In 10 $(5.4 \%)$ cases there was family history of Diabetes Mellitus while in $44(23.7 \%)$ cases there was family history of Obesity. In 40 $(21.5 \%)$ cases there was no single risk factor in family in 67 $(36.0 \%)$ case there was at least one risk factor present in family. While in $4(2.2 \%)$ of case all four risk factors were present in family.

In $39(21 \%)$ cases there was family history of CHD either in either parents or in brothers or sisters, including one case in which there was history of both the parents suffering from CHD. Chadda S.L., et al found family history of CHD associated with occurrence of CHD. In that study $25.8 \%$ of subjects, $27.4 \%$ of males and $23.6 \%$ of females had given positive family history of CHD [11].

\section{Manifestation of Disease}

Table 4 shows that rate of detection of new cases increases with increasing age in both sexes, especially, more among females. Proportion of newly detected cases in males is $45.2 \%$ and in females $61.7 \%$. Among the subjects 92 (49.5\%) were known cases of $\mathrm{CHD}$ while $94(50.5 \%)$ were newly detected. Maximum numbers of newly detected cases were in the age group of 45 to 54 years.

Table 4- Old and New Cases of CHD by Age \& Sex

\begin{tabular}{|c|c|c|c|c|c|c|c|c|c|}
\hline \multirow{2}{*}{ Age } & \multicolumn{3}{|c|}{ Male } & \multicolumn{3}{|c|}{ Female } & \multicolumn{3}{|c|}{ Total } \\
\hline & Old & New & Total & Old & New & Total & Old & New & Total \\
\hline $25-34$ & - & - & - & $1(100)$ & - & $1(100)$ & $1(100)$ & - & $1(100)$ \\
\hline $35-44$ & $4(100)$ & - & $4(100)$ & $3(75)$ & $1(25)$ & $4(100)$ & $7(87.5)$ & $1(12.5)$ & $8(100)$ \\
\hline $45-54$ & $6(40)$ & $9(60)$ & $15(100)$ & $4(23.5)$ & $13(76.5)$ & $17(100)$ & $10(31.3)$ & $22(68.8)$ & $32(100)$ \\
\hline $55-64$ & $59(55.1)$ & $48(44.9)$ & $107(100)$ & $15(39.5)$ & $23(60.5)$ & $38(100)$ & $74(51.0)$ & $71(49.0)$ & $145(100)$ \\
\hline Total & $69(54.8)$ & $57(45.2)$ & $126(100)$ & $23(38.3)$ & $37(61.7)$ & $60(100)$ & $92(49.5)$ & $94(50.5)$ & $186(100)$ \\
\hline
\end{tabular}

Figures in parenthesis indicate row percentage

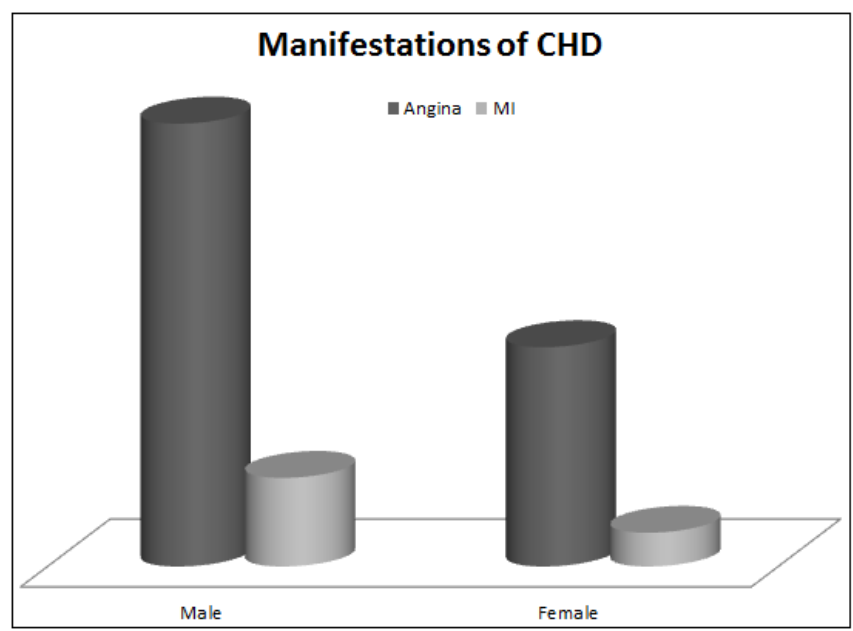

Fig. 3- Manifestations of $\mathrm{CHD}$

Table 5 shows, $15.6 \%$ of the subjects had given history of Myocardial Infarction (MI) while 84. 4\% had only Anginal Pain (AP). One male in the age group of 45 to 54 years was found to be suffered from Myocardial Infarction, on ECG, but history was obtained only of anginal pain. There was no significant difference among males and females in manifestation of disease $(P<0.05)$. In the study done by Chadda S.L. $32.9 \%$ were having MI while $67.1 \%$ had complaint of Angina [11].

Table 5- Manifestations of CHD by Age \& Sex

\begin{tabular}{|c|c|c|c|c|c|c|c|c|c|}
\hline \multirow{2}{*}{ Age } & \multicolumn{3}{|l|}{ Male } & \multicolumn{3}{|l|}{ Female } & \multicolumn{3}{|l|}{ Total } \\
\hline & MI & $\mathrm{AP}$ & Total & MI & $\mathrm{AP}$ & Total & MI & $\mathrm{AP}$ & Total \\
\hline $25-34$ & - & - & - & - & $1(100)$ & $1(100)$ & - & $1(100)$ & $1(100)$ \\
\hline $35-44$ & - & $4(100)$ & $4(100)$ & $1(25)$ & $3(75)$ & $4(100)$ & $1(12.5)$ & $7(87.5)$ & $8(100)$ \\
\hline $45-54$ & $1(6.7)$ & $14^{*}(93.3)$ & $15(100)$ & $1(5.9)$ & $16(94.1)$ & $17(100)$ & $2(6.2)$ & $30(93.8)$ & $32(100)$ \\
\hline $55-64$ & $20(18.7)$ & 87 (81.3) & $107(100)$ & $6(15.8)$ & $32(84.2)$ & $38(100)$ & $26(17.9)$ & $119(82.1)$ & $145(100)$ \\
\hline Total & 21 (16.7) & $105(83.3)$ & $126(100)$ & $8(13.3)$ & $52(86.7)$ & $60(100)$ & $29(15.6)$ & $157(84.4)$ & $186(100)$ \\
\hline
\end{tabular}

Figures in parenthesis indicate row percentage MI - Myocardial Infarction AP: Anginal Pain

*One case was found to be suffered from Myocardial Infarction on ECG but history was obtained only of angina.

Table 6 shows that, when asked about type of pain, $88.7 \%$ felt that it was difficult to describe the type of pain. On further enquiry 
most of them mentioned that it was dull ache character. The $91.4 \%$ cases experience pain while walking uphill, while $8.6 \%$ of cases avoid walking uphill. The $27.4 \%$ subjects feel pain while walking at ordinary pace. The $47.8 \%$ take sublingual Sorbitrate while $47.3 \%$ stop walking and $4.8 \%$ slows down in response to chest pain. The $80.1 \%$ mentioned that pain stops in less than 5 minutes while $19.9 \%$ mentioned that it takes more than 5 minutes but less than 10 minutes to stop the pain.

Table 6- Salient features of History and Examination in cases of Coronary Heart Disease

\begin{tabular}{|c|c|c|}
\hline \multicolumn{3}{|l|}{ 1. Type of Pain } \\
\hline Cannot describe & 165 & $88.70 \%$ \\
\hline Dull ache & 171 & $91.90 \%$ \\
\hline \multicolumn{3}{|l|}{ 2. Pain while walking } \\
\hline Uphill & 170 & $91.40 \%$ \\
\hline Ordinary Pace & 51 & $27.40 \%$ \\
\hline \multicolumn{3}{|l|}{ 3. Response to chest pain } \\
\hline Slow & 9 & $4.80 \%$ \\
\hline Stop & 88 & $47.30 \%$ \\
\hline Take SL Pill & 89 & $47.80 \%$ \\
\hline \multicolumn{3}{|l|}{ 4. Time for relief of Chest Pain } \\
\hline Below 5 min & 149 & $80.10 \%$ \\
\hline $5-10 \min$ & 37 & $19.90 \%$ \\
\hline \multicolumn{3}{|l|}{ 5. Site of chest Pain } \\
\hline Upper Sternum & 18 & $9.70 \%$ \\
\hline Lower Sternum & 17 & $9.10 \%$ \\
\hline Precordium & 43 & $23.10 \%$ \\
\hline Upper \& Lower Sternum & 96 & $51.60 \%$ \\
\hline Precordium \& Left arm & 12 & $6.50 \%$ \\
\hline \multicolumn{3}{|l|}{ 6. Duration of Chest Pain } \\
\hline $0-5$ months & 10 & $5.40 \%$ \\
\hline 6-11 months & 87 & $46.80 \%$ \\
\hline $12-23$ months & 59 & $31.70 \%$ \\
\hline 24-35 months & 12 & $6.40 \%$ \\
\hline $36-59$ months & 11 & $5.90 \%$ \\
\hline 60 months \& above & 7 & $3.80 \%$ \\
\hline \multicolumn{3}{|l|}{ 7. Duration of Ml } \\
\hline $0-5$ months & 2 & $6.90 \%$ \\
\hline 6-11 months & 6 & $20.70 \%$ \\
\hline $12-23$ months & 8 & $27.60 \%$ \\
\hline 24-35 months & 3 & $10.30 \%$ \\
\hline $36-59$ months & 4 & $13.80 \%$ \\
\hline 60 months \& above & 6 & $20.70 \%$ \\
\hline \multicolumn{3}{|l|}{ 8. Presence of related IIIness } \\
\hline Hypertension & 146 & $78.50 \%$ \\
\hline Diabetes & 17 & $9.10 \%$ \\
\hline CVA & 5 & $2.70 \%$ \\
\hline \multicolumn{3}{|l|}{ 9. Family History } \\
\hline No risk factor & 40 & $21.50 \%$ \\
\hline Smoking & 131 & $70.40 \%$ \\
\hline Hypertension & 60 & $32.20 \%$ \\
\hline Diabetes & 10 & $5.40 \%$ \\
\hline Obesity & 44 & $23.70 \%$ \\
\hline Any 1 risk factor & 67 & $36.00 \%$ \\
\hline Any 2 risk factor & 61 & $32.80 \%$ \\
\hline Any 3 risk factor & 14 & $7.50 \%$ \\
\hline All 4 risk factor & 4 & $2.20 \%$ \\
\hline Coronary Heart Disease & 39 & $21.00 \%$ \\
\hline \multicolumn{3}{|l|}{ 10. Smoking } \\
\hline More than 1 year & 124 & $66.70 \%$ \\
\hline \multicolumn{3}{|l|}{ 11. Alcohol Consumption } \\
\hline More than 1 year & 58 & $31.20 \%$ \\
\hline 12. Tobacco Chewers & 103 & $55.40 \%$ \\
\hline \multicolumn{3}{|l|}{ 13. Nourishment } \\
\hline Malnourished & 6 & $3.20 \%$ \\
\hline Average & 75 & $40.30 \%$ \\
\hline Well-nourished & 105 & $56.50 \%$ \\
\hline
\end{tabular}

Table 6 Continues

\begin{tabular}{|c|c|c|}
\hline \multicolumn{3}{|l|}{ 14. Built } \\
\hline Ectomorph & 12 & $6.50 \%$ \\
\hline Mesomorph & 94 & $50.50 \%$ \\
\hline Endomorph & 80 & $43.00 \%$ \\
\hline 15. Pallor & 21 & $11.30 \%$ \\
\hline \multicolumn{3}{|l|}{ 16. Clubbing } \\
\hline No & 171 & $91.90 \%$ \\
\hline Grade I & 2 & $1.10 \%$ \\
\hline Grade II & 11 & $5.90 \%$ \\
\hline Grade III & 2 & $1.10 \%$ \\
\hline 17. Oedema feet & 23 & $12.40 \%$ \\
\hline 18. Oedema face & 6 & $3.20 \%$ \\
\hline \multicolumn{3}{|l|}{ 19. Other Illness } \\
\hline COPD & 30 & $16.10 \%$ \\
\hline MVP & 1 & $0.50 \%$ \\
\hline RHD & 1 & $0.50 \%$ \\
\hline Psoriasis & 1 & $0.50 \%$ \\
\hline Cervical Spondylitis & 1 & $0.50 \%$ \\
\hline \multicolumn{3}{|l|}{ 20. Systemic Examination } \\
\hline Basal Crepitation + & 43 & $23.10 \%$ \\
\hline Raised JVP & 1 & $0.50 \%$ \\
\hline S3+ Gallop & 1 & $0.50 \%$ \\
\hline Hepatomegaly & 4 & $2.20 \%$ \\
\hline Splenomegaly & 5 & $2.70 \%$ \\
\hline Hemiplegia & 5 & $2.70 \%$ \\
\hline \multicolumn{3}{|l|}{ 21. Fundoscopy } \\
\hline NP (Cataract) & 32 & $17.20 \%$ \\
\hline Normal & 74 & $39.8 \%$ \\
\hline HT Change Gr. I & 41 & $22.00 \%$ \\
\hline HT Change Gr. II & 29 & $15.60 \%$ \\
\hline HT Change Gr. III & 6 & $3.20 \%$ \\
\hline HT Change Gr. IV & 1 & $0.50 \%$ \\
\hline DM Changes & 3 & $1.60 \%$ \\
\hline \multicolumn{3}{|l|}{ 22. Electrocardiogram } \\
\hline WNL & 62 & $33.30 \%$ \\
\hline LVH & 26 & $14.00 \%$ \\
\hline Conduction Defects & 5 & $2.70 \%$ \\
\hline Ischemia* & 63 & $33.90 \%$ \\
\hline Infarct * & 30 & $16.10 \%$ \\
\hline
\end{tabular}

\section{*based on Minnesota Code}

Majority of subjects gave the history of onset of chest pain within last two years and only $3.8 \%$ had given history suffering for 5 or more than 5 years. While among 21 males and 8 females, those who had suffered from myocardial infarct, $66.2 \%$ had suffered within last two years and $20.7 \%$ were alive for five or more years after suffering from Ml. Due to fatal nature of infarct the community based cross sectional study cannot comment on survival.

\section{Hypertension}

As it can be seen from Table 7, in the age group of 55 to 64 years 81 males $(75.7 \%)$ and 31 females (81.6\%) were suffering from hypertension. The mean systolic blood pressure of all 186 subjects was 161.8 (SD-18.4 \& SE-1.35) while mean diastolic blood pressure was 97.6 (SD-10.3 \& SE-0.76). Majority of cases (101$54.3 \%$ ) were having systolic blood pressure in the range of 160 179 , while only in 41 cases the diastolic blood pressure was less than 90 .

Among the 146 hypertensive 125 were known cases of hypertension. Of these 55 were prescribed diuretics, 50 centrally acting antihypertensive, 3 beta blockers, 6 Calcium Channel blockers while 11 a non-specific treatment. But with very few exceptions none of them were taking treatment adequately or regularly. 
In epidemiological study of CHD in Delhi, hypertension emerged as the strongest associated risk factor in CHD in both sexes. The $43.8 \%$ of subjects, $42.1 \%$ of males and $46.2 \%$ of females were having hypertension [11].

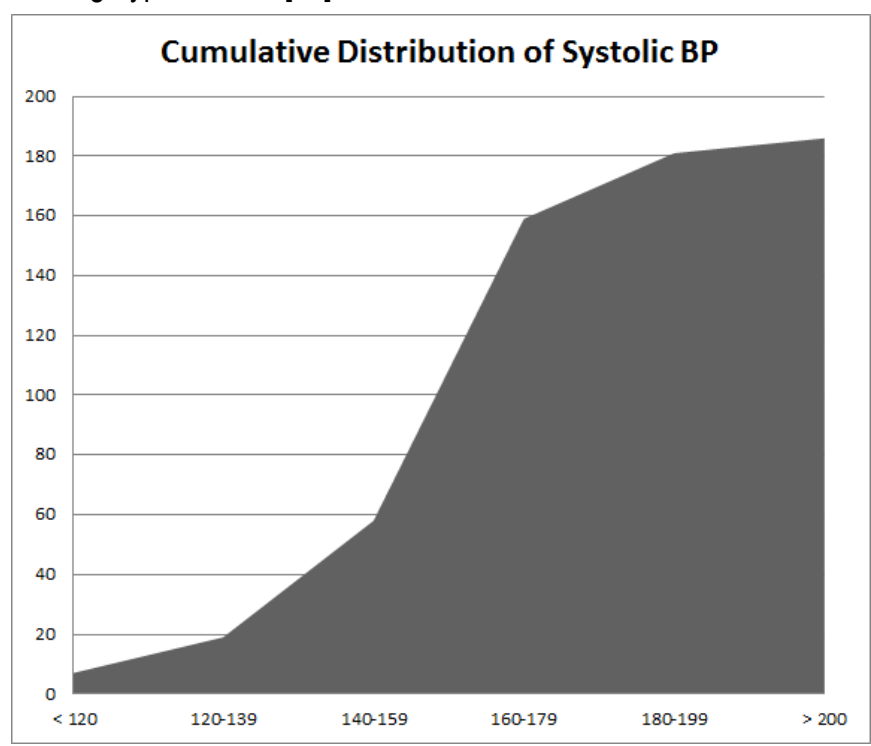

Fig. 4-Cumulative Distribution of Systolic BP

Table 7- Hypertension by Age \& Sex

\begin{tabular}{lllllll} 
Age & \multicolumn{3}{c}{ Male } & & \multicolumn{3}{c}{ Female } \\
Group & Hypertensive & Non- HT & Total & Hypertensive & Non- HT & Total \\
$25-34$ & - & - & - & $1(100)$ & - & $1(100)$ \\
$35-44$ & $4(100)$ & - & $4(100)$ & $3(75)$ & $1(25)$ & $4(100)$ \\
$45-54$ & $11(73.3)$ & $4(26.7)$ & $15(100)$ & $15(88.2)$ & $2(11.8)$ & $17(100)$ \\
$55-64$ & $81(75.7)$ & $26(24.3)$ & $107(100)$ & $31(81.6)$ & $7(18.4)$ & $38(100)$ \\
Total & $96(71.2)$ & $30(23.8)$ & $126(100)$ & $50(83.3)$ & $10(16.7)$ & $60(100)$ \\
\hline
\end{tabular}

Figures in parenthesis indicate row percentage

\section{Diabetes Mellitus}

Table 8 shows that 6 males (4.8\%) and 11 females (18.3\%) were suffering from Diabetes among the study group. The mean fasting blood sugar level was 104.4 (SD - 27.8 SE - 2.03) while mean post lunch sugar was 142.6 (SD-40.0 SE-2.93).

Chadda S.L., et al found relationship of diabetes with CHD. The $15.8 \%$ of clinically diagnosed CHD cases, $17.5 \%$ males and $13.4 \%$ females were suffering from diabetes [11].

Table 8- Diabetes Mellitus by Age \& Sex

\begin{tabular}{lllllll|}
\multirow{2}{*}{ Age Group } & \multicolumn{3}{c}{ Male } & \multicolumn{3}{c}{ Female } \\
\cline { 2 - 7 } & Diabetes & Non- DM & Total & Diabetes & Non- DM & Total \\
$25-34$ & - & - & - & - & - & $1(100)$ \\
$35-44$ & $2(50.0)$ & $2(50.0)$ & $4(100)$ & - & $4(100)$ & $4(100)$ \\
$45-54$ & $2(13.3)$ & $13(86.7)$ & $15(100)$ & $4(23.5)$ & $13(76.5)$ & $17(100)$ \\
$55-64$ & $2(01.9)$ & $105(98.1)$ & $107(100)$ & $7(18.4)$ & $31(81.6)$ & $38(100)$ \\
Total & $6(4.8)$ & $120(95.2)$ & $126(100)$ & $11(18.3)$ & $49(81.7)$ & $60(100)$ \\
\hline
\end{tabular}

Figures in parenthesis indicate row percentage

\section{Obesity, Cholesterol and Diet}

In 53 males (42.1\%) Body Mass Index values were above normal while $1(0.8 \%)$ was obese. In females $7(11.7 \%)$ had BMI values above normal but $12(20 \%)$ were obese. Chadda S.L., et al had used weight above $10 \%$ of expected weight (as decided by LIC India) as criteria for obesity and found obesity related with $\mathrm{CHD}$ [11]. In their study $42 \%$ of those who had a heart problem were obese, while just $30 \%$ of obese were happily fat without a heart problem.

The mean total cholesterol was 255.30 (SD-41.1 SE-3.0). Only 13 cases (7\%) had total cholesterol levels were below $200 \mathrm{mg} / \mathrm{dl}$ while $73 \%$ had levels above $240 \mathrm{mg} / \mathrm{dl}$. Chadda S.L. found cholesterol more than $200 \mathrm{mg} / \mathrm{dl}$ in $30 \%$ of CHD cases [11].

The 51 cases $(27.4 \%)$ were receiving 2800 or more calories through daily diet and $40(21.6 \%)$ cases were receiving less than 2400 calories through daily food. In majority of cases i.e. 133 $(71.6 \%)$ more than $20 \%$ of calories of the total caloric intake were derived from fat. But only $3.8 \%$ cases were eating fats amounting $30 \%$ or more of total calories. Out of 186101 (54.3\%) had habit of taking additional salt in diet. Considering limitations of 24 hour recall survey method of dietary survey included in the study, it needs further evaluation.

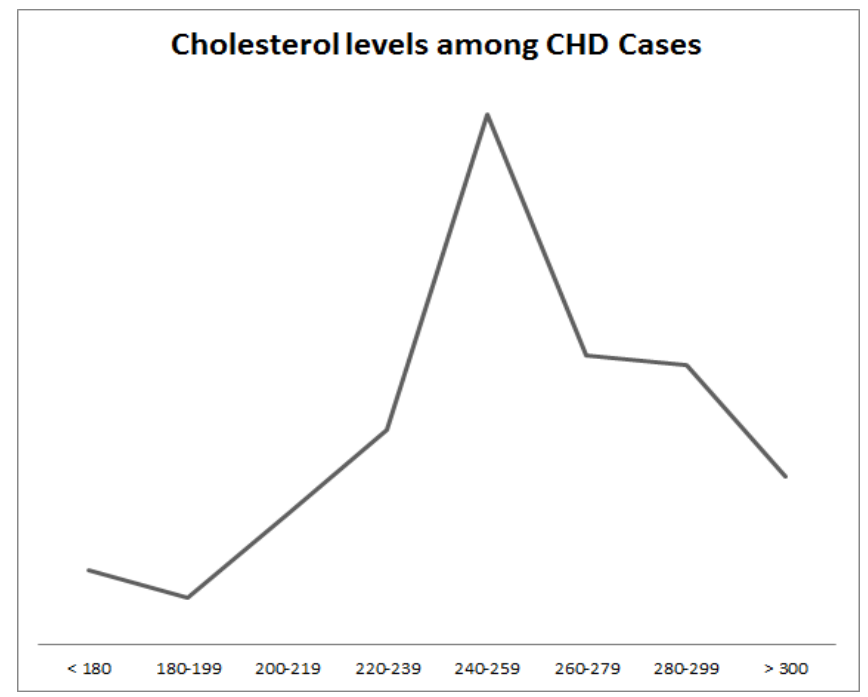

Fig. 5- Cholesterol levels among CHD Cases

\section{Smoking, Alcohol Consumption and Tobacco Chewing}

Among cases $66.7 \%$ were smokers while $39.8 \%$ had given history of passive smoking. In epidemiological study of CHD in Delhi [11] smoking did not show independent association with $\mathrm{CHD}$, though it was present in $36.5 \%$ males and $5.9 \%$ females. The criteria they had used was person smoking 10 cigarettes per day for two years or more at the time of survey [11].

Out of 186 there were $58(31.2 \%)$ alcohol consumers while 103 $(55.4 \%)$ were tobacco chewers.

\section{Knowledge}

As shown in Table 9 among the known cases of CHD, 19 (20.7\%) had no knowledge about hypertension, $17(18.5 \%)$ had no knowledge that smoking is a risk factor, $40(43.5 \%)$ had no idea that alcohol is a risk factor while $84(91.3 \%)$ were not aware about relation between dietary factors and $\mathrm{CHD}$. Also it was noted that, $81(88.0 \%)$ had no knowledge about Diabetes Mellitus.

Among 124 smokers (out of total 186 case) as the Table 10 shows, $71(57.3 \%)$ were smoking same as in the past at the time 
of survey, $24(19.4 \%)$ had decreased the number, 22 (17.7\%) were smoking occasionally while $7(5.6 \%)$ had stopped smoking.

\section{Table 9- Knowledge about risk factors of $\mathrm{CHD}$}

\begin{tabular}{|c|c|c|c|c|c|c|c|c|}
\hline \multirow[b]{2}{*}{ Knowledge } & \multicolumn{2}{|c|}{ Hypertension } & \multicolumn{2}{|c|}{ Smoking } & \multicolumn{2}{|c|}{ Alcohol } & \multicolumn{2}{|c|}{ Dietary factors } \\
\hline & $\begin{array}{l}\text { Known } \\
\text { Case }\end{array}$ & $\begin{array}{l}\text { Newly } \\
\text { Detected }\end{array}$ & $\begin{array}{l}\text { Known } \\
\text { Case }\end{array}$ & $\begin{array}{l}\text { Newly } \\
\text { Detected }\end{array}$ & $\begin{array}{l}\text { Known } \\
\text { Case }\end{array}$ & $\begin{array}{l}\text { Newly } \\
\text { Detected }\end{array}$ & $\begin{array}{l}\text { Known } \\
\text { Case }\end{array}$ & $\begin{array}{l}\text { Newly } \\
\text { Detected }\end{array}$ \\
\hline No & $\begin{array}{l}19 \\
(20.7)\end{array}$ & $\begin{array}{l}47 \\
(50)\end{array}$ & $\begin{array}{l}17 \\
(18.5)\end{array}$ & $\begin{array}{l}20 \\
(21.3)\end{array}$ & $\begin{array}{l}40 \\
(43.5)\end{array}$ & $\begin{array}{l}50 \\
(53.2)\end{array}$ & $\begin{array}{l}84 \\
(91.3)\end{array}$ & $\begin{array}{l}92 \\
(97.9)\end{array}$ \\
\hline Satisfactory & $\begin{array}{l}72 \\
(78.2)\end{array}$ & $\begin{array}{l}45 \\
(47.9)\end{array}$ & $\begin{array}{l}73 \\
(79.3)\end{array}$ & $\begin{array}{l}73 \\
(77.6)\end{array}$ & $\begin{array}{l}51 \\
(55.4)\end{array}$ & $\begin{array}{l}43 \\
(45.7)\end{array}$ & $\begin{array}{l}7 \\
(7.6)\end{array}$ & $\begin{array}{l}2 \\
(2.1)\end{array}$ \\
\hline Good & $\begin{array}{l}1 \\
\text { (1.1) }\end{array}$ & $\begin{array}{l}2 \\
(2.1)\end{array}$ & $\begin{array}{l}2 \\
(2.2)\end{array}$ & $\begin{array}{l}1 \\
\text { (1.1) }\end{array}$ & $\begin{array}{l}1 \\
\text { (1.1) }\end{array}$ & $\begin{array}{l}1 \\
\text { (1.1) }\end{array}$ & $\begin{array}{l}1 \\
\text { (1.1) }\end{array}$ & \\
\hline Total & $\begin{array}{l}92 \\
(100)\end{array}$ & $\begin{array}{l}94 \\
(100)\end{array}$ & $\begin{array}{l}92 \\
(100)\end{array}$ & $\begin{array}{l}94 \\
(100)\end{array}$ & $\begin{array}{l}92 \\
(100)\end{array}$ & $\begin{array}{l}94 \\
(100)\end{array}$ & $\begin{array}{l}92 \\
(100)\end{array}$ & $\begin{array}{l}94 \\
(100)\end{array}$ \\
\hline
\end{tabular}

Figures in parenthesis indicate column percentage

Table 10- Knowledge about smoking as a risk factor and current smoking habits

\begin{tabular}{|llllll|} 
Knowledge & $\begin{array}{l}\text { No change in } \\
\text { smoking habits the number }\end{array}$ & $\begin{array}{l}\text { Decreased } \\
\text { smocasionally }\end{array}$ & $\begin{array}{l}\text { Stopped } \\
\text { smoking }\end{array}$ & Total \\
\hline No & $3(23.1)$ & $8(61.5)$ & - & $2(15.4)$ & $13(100)$ \\
Satisfactory & $67(61.5)$ & $15(13.8)$ & $22(20.2)$ & $5(4.6)$ & $109(100)$ \\
Good & $1(50.0)$ & $1(50)$ & - & - & $2(100)$ \\
Total & $71(57.3)$ & $24(19.4)$ & $22(17.7)$ & $7(5.6)$ & $124(100)$ \\
\hline
\end{tabular}

Figures in parenthesis indicate row percentage

As Table 11 shows only $10(5.4 \%)$ cases were having satisfactory knowledge about dietary risk factors of CHD. The level of knowledge was better among highly educated subjects.

All the above findings show that knowledge about CHD and its risk factor is very poor in general.

Table 11- Literacy level and knowledge about dietary risk factors

\begin{tabular}{|llll|}
\multicolumn{3}{c}{ in CHD case } \\
Education & NO & Satisfactory & Total \\
Illiterate & $116(65.9)$ & $4(40.0)$ & $120(64.5)$ \\
$1-4$ & $44(25.0)$ & - & $44(23.7)$ \\
$5-7$ & $11(6.3)$ & - & $11(5.9)$ \\
$8-10$ & $4(2.3)$ & $3(30.0)$ & $7(3.8)$ \\
Graduate & $1(0.6)$ & $3(30.0)$ & $4(2.2)$ \\
Total & $176(100)$ & $10(100)$ & $186(100)$ \\
\hline
\end{tabular}

figures in parenthesis indicate column percentage.

\section{Conclusion and Recommendations}

The present cross-sectional community based study indicates that Coronary Heart Disease as assessed by Rose Questionnaire is of a magnitude that makes it a major problem of public health importance even in urban slum population having predominantly low socio-economic status.

Prevalence of Coronary Heart Disease in this community was 15.8 per thousand in the age group of 25 to 64 years. In males prevalence was 20.8 per thousand while in females it was 10.5 per thousand. Minimum prevalence rate was 15.46 per thousand. It was found that:

- $\mathrm{CHD}$ is more prevalent in males than in females.

- $\mathrm{CHD}$ is most prevalent in the age group of 55 to 64 years in both males and females. $(P<0.01)$

- Angina Pectoris is the commonest manifestations of CHD.
- The $50 \%$ of CHD cases neglect their symptoms of angina pectoris and delay in seeking medical advice. The proportion is high in females.

- Proportion of risk factors is high among the cases

- Knowledge about the $\mathrm{CHD}$ is poor in general in this community.

$\mathrm{CHD}$ is a multifactorial disease. Despite some lingering, uncertainties and incomplete knowledge, we have enough information to act effectively. The dramatic decline in morbidity and mortality caused by $\mathrm{CHD}$ in some countries has been substantial, sustained and real. The proof of the benefit of modifying risk factors for $\mathrm{CHD}$ is mounting.

Community health physicians have to play a vital role in dispelling, feeling of complacency and emphasizing the primary preventive approach to tackle this public health problem which has assumed epidemic proportions. Given the importance of applying prevention strategies early in life, schools and youth education programme can be important focus for preventive activities. Social learning theory, the diffusion and adoption theory and community development research may all be utilized in the planning of community based health education. Use of mass media along with sustained personal reinforcement over a long period can definitely help effectively to curb widely spreading disease.

Early detection and proper treatment of hypertension and diabetes can help in controlling or delaying the onset of CHD. Along with provision of health clinic a "Hypertension Clinic: must be an integral part of community health centre. The hypertension clinic staff must consist, a medical social worker, a physician with experience of minimum 6 months in cardiology and at least one community health worker. All the newer more effective drugs and needed instruments as well facility for simple routine investigations should be available. Non pharmacological means of treating hypertension should also be stressed upon. More importance need to be given to traditional age old Indian methods, Yoga and Meditation.

Though tobacco chewing and smoking can be controlled through behavioural changes brought by community education, Government, National Medical associations and other influential organizations like Rotary have a much important role to play.

Efforts should be made to change dietary practices of the community to healthy one through health education which should start from childhood. Government should implement agricultural and food policies to promote the development of low fat products by meat and dairy industries and to increase the consumption of fruits, vegetables and cereal based products, which have high fibre content.

Considering the role of silent ischemia in manifestation of $\mathrm{CHD}$, ignorance about $\mathrm{CHD}$ and neglect of symptom by individual, the health education should create awareness among population. The ECG cannot be depended upon for diagnosis it should be advocated in the aged whom there is presence of risk factors but present with vague symptoms. The symptom of chest pain even if of a vague type should be investigated thoroughly before labelling the individual not suffering from CHD.

The psychological trauma, along with physical, has an impact, not only on individual but on whole family. Rehabilitation being related with survival of the individual, enough importance to this aspect is needed. 
Enough importance to topics of Hypertension and Coronary Heart Disease should be given in Medical curriculum of undergraduates. To obtain a composite picture for the whole country, large community based epidemiological studies will have to be conducted in different parts of the country. It will help the policy makers to chalk out programmes to minimize the extent of the problem of $\mathrm{CHD}$.

\section{Limitations of the Study}

A community based cross-sectional study with retrospective collection of data possesses some inherent limitations and present study was no exception. Prevalence of Coronary Heart Disease being very less it needs a large sample to draw and evaluate most reliable conclusions. Though effort was made to cover large population, it was not feasible to cover population larger than this.

The perfect and fool proof method of diagnosis of Coronary Heart Disease can be achieved by only Coronary Angiography an invasive investigation, which is neither indicated nor feasible for community based study. Considering the subjective nature of Angina Pectoris and perception of pain, silent and relatively silent ischemia cannot be detected by using Rose Questionnaire, which has its own limitations

\section{London School of Hygine Cardiovascular (Rose) Questionnaire}

\section{Section A: Chest Pain on Effort}

1. Have you ever had any pain or discomfort in your chest? i. Yes ii. No

2. Do you get it when you walk uphill or hurry? i. Yes ii. No iii. Never hurries or walks uphill

3. Do you get it when you walk at ordinary pace on the level? i. Yes ii. No

4. What do you do if you get it while you are walking? i. Stop or slow down ii. Carry on

iii. Carry on after taking SL Nitroglycerine

5. If you stand still, what happens to it?
i. Relieved
ii. Not relieved

6. How soon?

i. 10 minutes or less ii. More than 10 minutes

7. Will you show me where it was?
i. Sternum (Upper or Middle)
iii. Left anterior chest
ii. Sternum (Lower)
v. Other: Specify
iv. Left arm

8. Do you feel it anywhere else?

i. Yes, Specify ii. No

\section{Section B: Possible Infarction}

9. Have you ever had a severe pain across the front of your chest lasting for half an hour or more?

i. Yes ii. No

Criteria for Angina Pectoris

1 (i) 2 OR 3 (i) 4 (i), (iii) 5 (i) 6 (i)

\section{Proforma}

Epidemiological Study of Coronary Heart Disease

1. Name:

2. Age:

3. Sex: Male/Female

4. Religion: $\quad H / C / M / O t h e r$

5. Marital Status: M/S/W/D

6. Address:

7. Education: Illiterate/ 1-4/5-7/8-10/Graduate/Tech. Diploma/

P.G./Tech. Degree

8. Staying in Cheeta Camp: Yrs.

9. Drinking Water: Tap/Other Source Raw/Boiled/

Filtered

10. Type of Family: Nuclear/Joint/Ext. Joint

11. No. of Family members:

$\begin{array}{ll}\text { Male Adult } & \text { Male Children } \\ \text { Female Adult } & \text { Female Children }\end{array}$

12. No. of earning family members:

13. Family Income: Rs./month

14. Occupation:

15: Working Hrs.: $\quad /$ day

16. Type of work: Sedentary/ moderate / heavy

17. Physical Exercise apart from work: Yes/No Specify

18. Family history of $\mathrm{CHD}$ and its risk factors:

a) $\mathrm{H} / \mathrm{O} \mathrm{CHD}$ in parents or relatives Yes/No

Specify

b) H/O Sudden death in family $\quad$ Yes/No

If yes, Name-

Age at Death

Probable cause of Death- CHD / CVA / Any other / Don't Know

c) H/o Risk factors in family

1) Smoking Yes/No

2) Hypertension Yes/No

3) Obesity Yes/No

4) Diabetes Mellitus Yes/No

19. History of Angina Pectoris: (Refer Rose Questionnaire)

20. Known case of: $\quad \mathrm{CHD} / \mathrm{DM} / \mathrm{HT} / \mathrm{Any}$ other/NA

Details-

21. History suggestive of:

Diabetes Mellitus Yes/No

Hypertension Yes/No

If yes, Details-

22. H/o present complaints:

23. Addiction:

Tobacco Bidi Cigarette Alcohol Any other

a) Started at

b) Quantity I

c) Period I

d) Quantity II

e) Period II

f) If Smoker, Complete inhalation $\quad$ Yes/No

g) Currently Smoke: Yes/No

24. Passive Smoking: $\quad$ Yes/No

25. Diet:

a) Type- $\quad$ Veg/Mixed

b) Food items consumed in last $24 \mathrm{Hrs}$.

Breakfast- 
Lunch-

Dinner-
c) Do you take extra salt in diet?
Yes/No

\section{Examination}

\section{General Examination}
a) Nourishment:
Average/Malnourished/Well nourished
b) Built: Ectomorph/Mesomorph/Endomorph
c) Height:
d) Weight:
e) Febrile:
Yes/No
f) Pallor:
Yes/No
g) Clubbing:
Yes/No
h) Oedema feet
Yes/No
i) Oedema face:
Yes/No
j) Ear lobe Crease Yes/No
k) Pulse: 1)
l) Respiratory Rate:
m) Blood Pressure:

$\begin{array}{ll}\text { Standing } & \text { 1) } \\ \text { Sitting } & \text { 1) } \\ \text { Supine } & \text { 1) }\end{array}$
n) Any Other:

\section{Systemic Examination}

a) RS:

b) CVS:

c) PA:

d) CNS:

e) Fundoscopy:

$\begin{array}{lll}\text { Diabetic Changes: } & \text { Yes/No } & \text { Grade } \\ \text { Hypertensive Changes } & \text { Yes/No } & \text { Grade }\end{array}$

\section{Investigation}

1. Haemoglobin:
2. Urine:
Sugar
3. Blood Sugar:
Albumin
Microscopic
Fasting Post prandial

4. Serum cholesterol:
[3] Mahajan B.K. (1992) Methods in Biostatistics for Medical Students and Research Workers; 5th edition.

[4] Rose G.A., Blackburn H., Gillum R.F., Prineas R.J. (1982) Cardio-vascular Survey Methods, 2nd Edition.

[5] Gupta M.C., Mahajan B.K. (1991) Textbook of Preventive and Social Medicine, 1 st Edition, 86.

[6] WHO/FAO/UNU (1985) Energy and Protein Requirement; Technical report Series- 724.

[7] Padmavati S. (1962) Circulation, 25, 711.

[8] Mathur K.S. (1960) Circulation, 21, 684.

[9] Gupta S.P., Malhotra K.C. (1973) Journal of Association of Physicians India, 23, 885.

[10]Sinha P.R., Gaur S.D., Somani P.N. (1990) Indian Journal of community Medicine, XV(2), 82-84.

[11]Chadda S.L., Radhakrishnan S., Ramchandran K. (1990) Indian Journal of Medical Research [B] 92, 424-430.

[12]Sinha B.C. (1970) Journal of Indian Medical Association, 55, 171.

[13]Chadda S.L., Radhakrishnan S., Ramchandran K., Gopinath N. (1989) Indian Journal Community Medicine, XIV(4), 141147.

\section{Knowledge}

1. Knowledge about CHD No Satisfactory Good

2. Knowledge about HT No Satisfactory Good

3. Knowledge DM No Satisfactory Good

4. Knowledge about Smoking No Satisfactory Good

5. Knowledge about Alcohol No Satisfactory Good

6. Knowledge about Diet No Satisfactory Good

(Proforma Designed by Author)

\section{References}

[1] WHO (1985) Sudden Cardiac death; Technical Report Series726.

[2] WHO (1990) Prevention in Childhood and youth of Adult Cardiovascular disease: Time for Action; Technical Report Series792. 